\title{
HoD Detector, a System to Create Indicators about the Happiness of Citizens in a Smart City: Case of Study-GDL Smart City
}

\section{Raúl Beltrán Ramírez",2, Rocío Maciel Arellano, Leopoldo Gómez, Víctor Larios Rosillo, Carlos González Sandoval ${ }^{2}$}

${ }^{1}$ Departamento de Sistemas de Información, Universidad de Guadalajara Periférico Norte, Zapopan, México

${ }^{2}$ Centro de Enseñanza Técnica Industrial, Guadalajara, México

Email: jrbeltran@cucea.udg.mx,rmaciel@cucea.udg.mx,dr.leopoldo.gomez@ieee.org,

victor.m.lariosrosillo@ieee.org, carlos.augusto.gs@hotmail.com

How to cite this paper: Ramírez, R.B., Arellano, R.M., Gómez, L., Rosillo, V.L. and Sandoval, C.G. (2016) HoD Detector, a System to Create Indicators about the Happiness of Citizens in a Smart City: Case of StudyGDL Smart City. Journal of Software Engineering and Applications, 9, 524- 532. http://dx.doi.org/10.4236/jsea.2016.910035

Received: July 30, 2016

Accepted: October 25, 2016

Published: October 28, 2016

Copyright $\odot 2016$ by authors and Scientific Research Publishing Inc. This work is licensed under the Creative Commons Attribution International License (CC BY 4.0).

http://creativecommons.org/licenses/by/4.0/ (c) (i) Open Access

\begin{abstract}
Happiness is the ultimate goal for every living human being, and this condition motivates people to stay active and want to be alive. Having this feeling also fosters the proactivity of citizens. The opposite is depression, a condition capable of significantly affecting a person's behavior or perception. HoD Detector is a low-cost, easy to use application that aids in the diagnosis of a depressive disorder and motivates the user to seek professional help. The purpose of this study is to propose a way to measure happiness through the measurement of depression; to develop HoD Detector, evaluate the accuracy and usability of this application (with university students) for future enhancements of the system. The development of this application involved basic algorithms and the use of a database to successfully make a diagnosis and store the results of each user for further reference. The application is capable of giving a proper diagnosis with the time interval of $2-5$ minutes. HoD Detector has the potential to become an extremely useful tool to diagnose depression and motivate users to seek professional help not only in Mexico, but also on an international scale for improving in people's happiness condition.
\end{abstract}

\section{Keywords}

Smart Cities, Smart City Metrics, Mental Health, Happiness,

Depression, mHealth App

\section{Introduction}

In smart city metrics, the measure of happiness is a subjective indicator and a complex 
task to perform due to the many involved elements that impact to achieve this condition. However, the opposite of happiness could be depression which there is many concrete tests to detect this disorder in the subject of study. Hence we propose the HoD detector.

The amount of tasks that a smartphone can perform is steadily increasing on a daily basis, being financial, consulting the weather or news or even maintaining contact with loved ones from afar. HoD Detector is an application that explores these capabilities, considering that it can be used to perform a presumptive diagnosis of depression, a psychological disorder with serious consequences, which may encourage people to commit suicide, see Figure 1 for a window of suicides in Mexico. Having that in mind, it is only logical that developers take advantage this growing technological trend to create applications of considerable aid in the wellbeing of the population, bettering the living conditions of a Smart City's inhabitants. The latter's rapid diagnosis coupled with its user-friendly interface ensures a considerable impact on the concept of a Smart City and its smart living-health metric.

\section{Depressive Effect of Cities on Inhabitants}

\subsection{Importance of Smart City Metrics}

Due the multidimensionality of cities, which are indeed complex systems, because of the many variables interrelated, is important for city inhabitants and city decision makers [1] to identify and measure the status of those main key areas that impact on the city ecosystem, which may reflect the actual situation or "smartness" of the city.

The smartness of a city is a topic that may arise debate among actors [2], although is important for any city to establish a framework that states the main topics to promote and follow to progress in the smartness and evolve as a Smart City. To have a reference of the main key areas to keep focus on, we may consider the Boyd's Cohen wheel [3].

\subsection{City Indicators}

Cities need to work on a complex set of areas to evolve as a community and pose the best ecosystem for the inhabitants to evolve as a society and transcend. Some city indicators are explained in Table 1.

Happiness condition can be achieved on the presence of several situations that may "activate it". Nevertheless, happiness is quite complex to measure but the depression is the most measured. In fact there are more efforts to tackle depression, an important medical topic with specialized research.

Depression is a condition that significantly affects the mood of any person who suffers from it. A way to better understand this disease is by dividing it into 3 levels. The first being-symptomatic, the second level-syndromic, and the nosological level, which indicates the existence of a disorder in which the symptoms are not caused by another disease or condition, and therefore permitting us to diagnose a depressive disorder [5]. There are currently various types of questionnaires that help us define the level of depression (symptom, syndrome, clinical conditions) that a person may suffer from [6], we take as base the PHQ-9 validated questionnaire in order to elicit user's mood using a 


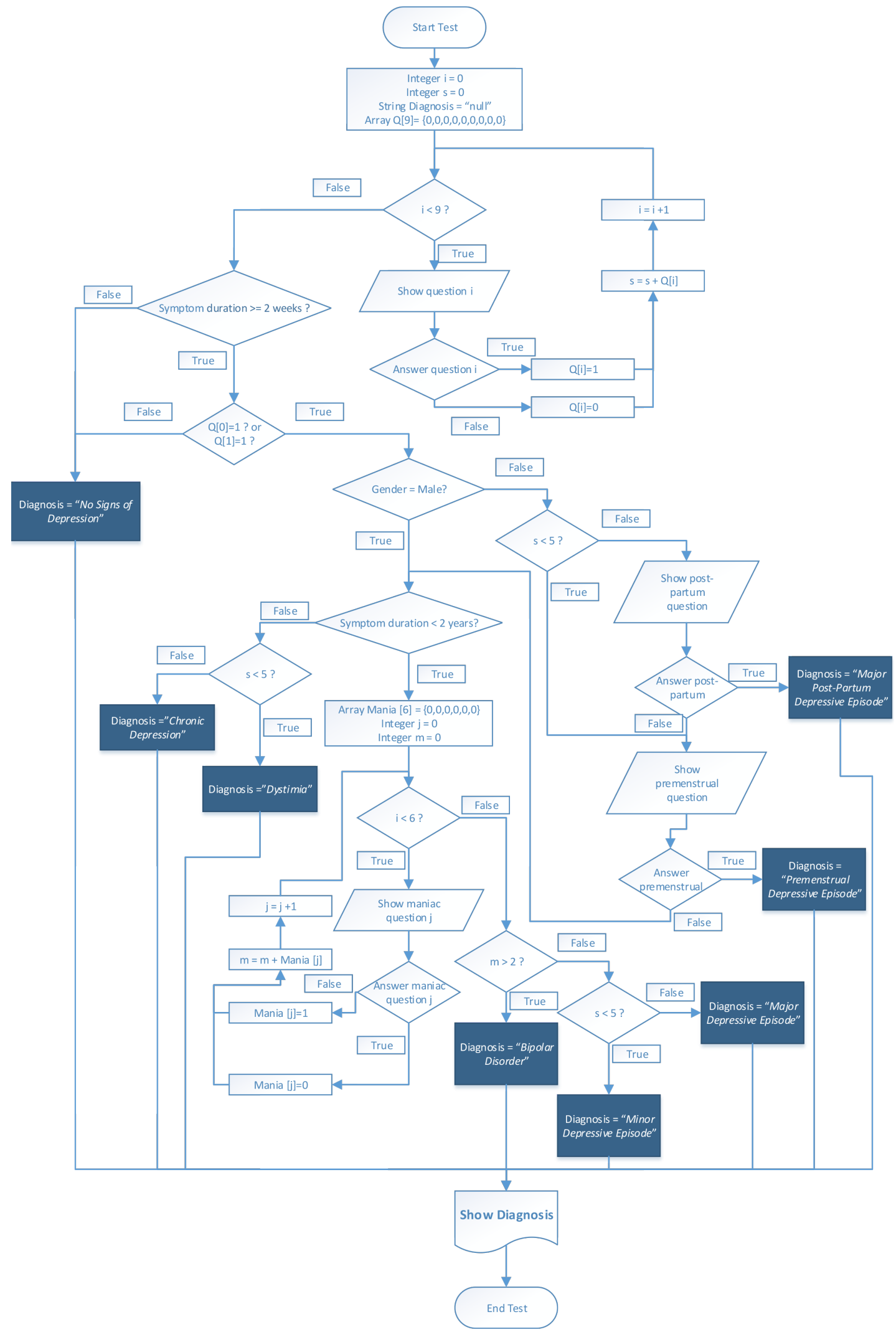

Figure 1. HoD Detector flow diagram. 
Table 1. Smart cities indicators.

\begin{tabular}{|c|c|c|}
\hline \multirow{2}{*}{ Indicator } & \multicolumn{2}{|l|}{ Smart Cities } \\
\hline & Context & Measurement plans \\
\hline Healthcare & $\begin{array}{l}\text { One of the most important indicators of any city is health } \\
\text { because the influence that poses this human aspect to the } \\
\text { wellbeing of people. This is associated to other indicators } \\
\text { that affects directly to it, moreover it is integrated by } \\
\text { unquantifiable number of situations that impact and } \\
\text { may decrease the level of health of the city inhabitants [4]. }\end{array}$ & $\begin{array}{l}\text { Population index } \\
\text { on clinical attention } \\
\text { centers. } \\
\text { M Health based } \\
\text { systems. } \\
\text { - Electronic mobile } \\
\text { based quality tests } \\
\text { on clinical centers. }\end{array}$ \\
\hline $\begin{array}{l}\text { Economic } \\
\text { productivity }\end{array}$ & $\begin{array}{l}\text { Money is one of the motors that motivate people to act } \\
\text { and develop solutions or products, provide services, } \\
\text { exploit natural resources to transforming them into things } \\
\text { that can be changed to an exchange rate that empowers } \\
\text { the capacity to acquire any other product or service. This } \\
\text { runs complex economic machinery in a system that may } \\
\text { inflates or diminish the expectation of purchasing power. }\end{array}$ & $\begin{array}{l}\text { - Modulator financial } \\
\text { institutions. } \\
\text { - Government } \\
\text { financial institutions. } \\
\text { - Financial } \\
\text { movements } \\
\text { for public access. }\end{array}$ \\
\hline $\begin{array}{l}\text { Environmental } \\
\text { Pollution }\end{array}$ & $\begin{array}{l}\text { Due the fact that people is mostly biological, close related } \\
\text { to natural environment, pollution affects directly and } \\
\text { negatively on people's health, physically and psychologically. }\end{array}$ & $\begin{array}{l}\text { - Suspended } \\
\text { particles on air } \\
\text { - Contaminated } \\
\text { water. } \\
\text { - } \text { Barren land } \\
\text { Dangerous } \\
\text { levels of noise. }\end{array}$ \\
\hline Happiness & $\begin{array}{l}\text { This condition of being happy is complex to measure, } \\
\text { is the feeling of well-being, that is the ultimate goal for } \\
\text { any living people, capable of transforming the perception } \\
\text { about the environment and society, negative feelings can } \\
\text { diminish people capacities, at least psychologically, } \\
\text { and could be perceived as impossible to surpass obstacles. } \\
\text { However, happiness is an ambiguous to measure feeling } \\
\text { due to its complexity, though the opposite is more } \\
\text { identifiable by means of naming methodologies and } \\
\text { techniques that measure those conditions making people } \\
\text { unhappy. It is been said, "If nothing happens, } \\
\text { is because everything is fine, but when something } \\
\text { occurs is immediately known". }\end{array}$ & $\begin{array}{l}\text { Measuring the } \\
\text { opposite side of } \\
\text { happiness } \\
\text { (depression) } \\
\text { with symptom } \\
\text { interpretation } \\
\text { tools due to } \\
\text { its complexity. }\end{array}$ \\
\hline
\end{tabular}

a. Smart cities frame indicators.

mobile app and then perform an analysis of their condition related to depression.

People's mood in a Smart city shall provide the level of "motivation" of people which also impacts on productivity, relationship between citizens, perception of environment, acceptance of public policies, etc. The results gathered from the HoD app may be useful to reinforce or take actions in those hot spots of the city. That is to say, if people that take the test obtain results of depressive disorder then, if they are joined in a public space then the city should provide an action to alleviate the situation. Also, having historical data about people evolution on the disorder can be determined the possible actions to take in the forthcoming events during the next days [7]. 


\section{Measuring Depression}

A study realized by Nelson Shen shows us an analysis of different applications (apps) for mobile devices pertaining to depression. This analysis portrays 243 applications approved by the study incorporating 5 principle topics such as: psychoeducation, symptom management, helpful resources, professional assistance (psychologists) and multipurpose. It is also divided in different categories: monitoring, auditory therapy, behavioral training, eBooks, among others (advice, lessons, spirituality, motivational) [8].

There are some measurement standards to help identify depression of people, the focus is aimed on symptomatology but not all of the approaches have the versatility to be adjusted to any methodology used or tools, as the used in this proposal. Some interesting ways to measure depression are: those of the ICHOM standard set for Depression \& Anxiety ${ }^{1}$, the criteria included in the DSM-IV- $\mathrm{V}^{1}$ as we used from [9] [10].

HoD Detector it's a user-friendly mobile application which gives an accurate depressive symptoms interpretation. This development can be used as a happiness metric tool on smart cities. The software was tested on young population between $18-25$ years at Guadalajara smart city.

The development of HoD Detector complies with the majority of the characteristics mentioned in aforementioned study because of the "helpful links" section that can be found on the main menu. This section of the application enables the user to find professional help, directs user to self-help websites, download auditory therapy apps, motivational links and help in general. The results section is where the answered questions are stored along with the user's diagnosis to allow the user to monitor his/her progress. We also included a photo gallery with many features that can distress the user and directly impact biogenic amine activity, specifically serotonin, modifying the behavior of the user and bettering his mood.

After the user completes the PHQ-9 test, information is uploaded to the cloud storage service thru the programed mechanism (see Figure 2).

\subsection{Algorithm and Flow Diagram}

Figure 1 represents the test menu algorithm, the questions are answered by dichotomy technique (yes or no answers), this was supported by the PHQ-9 (Patient Health Questionnaire 9) gold validated psychology tool. The diagnosis is saved into a real time MySQL Server database, all data will be available in the results menu to give a continuous monitoring mechanism to take advantage on disease progression.

\subsection{Our Specific Approach}

In order to obtain the level of depression, we have had assigned values to every diagnosis (see Table 2), process said values to obtain a numeric form of an otherwise intangible diagnosis, these values are mapped into one of a set of depression labels which de-

${ }^{1} \mathrm{HoD}$ Detector it's a user-friendly mobile application which gives an accurate depressive symptoms interpretation. This development can be used as a happiness metric tool on smart cities. The software was tested on young population between 18 - 25 years at Guadalajara smart city. 


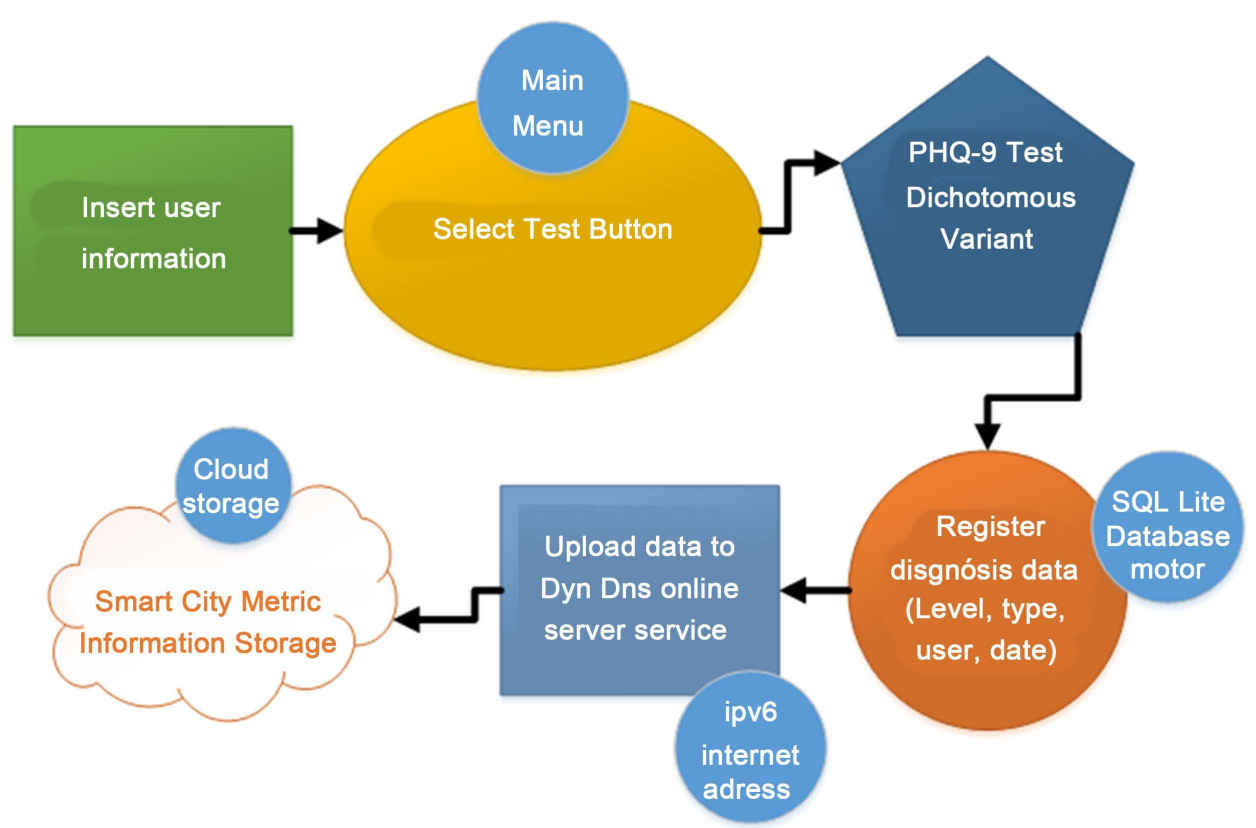

Figure 2. Data uploading mechanism inside HoD Detector app.

Table 2. HoD Detector diagnosis impact level.

\begin{tabular}{cccc}
\hline \multirow{2}{*}{ Diagnosis } & \multicolumn{3}{c}{ Levels of Depression } \\
\cline { 2 - 4 } & Stage & Impact level & Value \\
\hline No Signs of Depression & None & None & 0 \\
Minor Depressive Episode & Symptomatic & Slight & 1 \\
Major Depressive Episode & Syndromic & Regular & 2 \\
Premenstrual Depressive Episode & Symptomatic & Regular & 2 \\
Major Post-Partum Depressive Episode & Syndromic & Regular & 2 \\
Major Depresive Disorder & Nosologic & Moderate & 3 \\
Dystimia & Nosologic & High & 4 \\
Chronic Depression & Nosologic & Very High & 5 \\
\hline
\end{tabular}

a. Data obtained by DSM-VI criteria.

notes a level of this disorder, also some previous testing is performed to aware in the level of short term memory, retention, capacities that increase according several conditions associated to healthy people, that may be happy [11] [12].

The Happiness is relative and defined, as the overall appreciation of one's life-as-awhole, in short term, how much one likes the own life including daily tasks and also recreational activities, is a constant in different cultural contexts [13].

Equation 1: Obtains the average level, where " $n$ " is the number of user diagnosis per month and the "level" contains the values $(0-5)$ depending on the diagnosis value.

$$
\text { Month Level }=\frac{\left[\sum_{i=0}^{i=n} \operatorname{level}[n]\right]}{n}
$$


When using the app, we can estimate the type if the user has or not any type of depression; hence, it is possible to know the quantity of people that does not have depression by calculating the number of users that applied the test with depression over the total number of people that applied the test.

\section{Results}

\subsection{Application Interface}

HoD Detector was carefully designed to be simple to use and aesthetically pleasing, ensuring full motivation of the users. Figure 3 shows a screenshot of the application's interface.

The application supports the ability to input and view user history, depressive levels, and contact certificated institutes. This application also allows the viewing of past evaluations. All entries are logged with timestamps to ensure data consistency.

The design of the user interface allows the user to receive a diagnosis and his/her respective results in the time lapse of 2 - 5 minutes.

It was used a graph structure to model the logic steps available through the application. The used structure is based on true or false conditions that advance from the base (root) to the highest level (leaves) depending on the input conditions [14]. The associated graph-like algorithm employed in the HoD Detector's main sensing, where the root contains basic user information (age and gender) and depends on the Boolean Values that the user assigns to the symptoms in order to track nodes until a proper presumptive diagnosis is reached.

\subsection{Experiment Results}

The experiment was carried out on two important universities of Guadalajara, Universidad de Guadalajara and CETI, on a sample of 55 students, $60 \%$ of them were men. After applying the test to a group of scholars, we have found some interesting results, as shown in Figure 4, it can be identified the several depression disorders and the percentage of people with any of them, but the granularity of depression is not present in

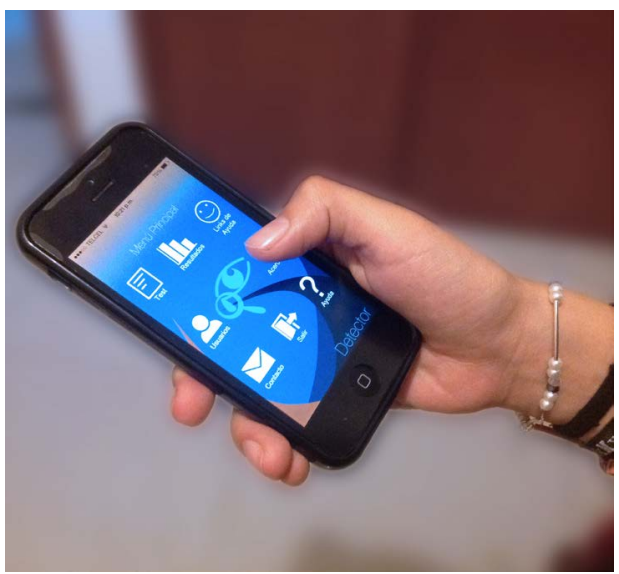

Figure 3. Application Interface. 

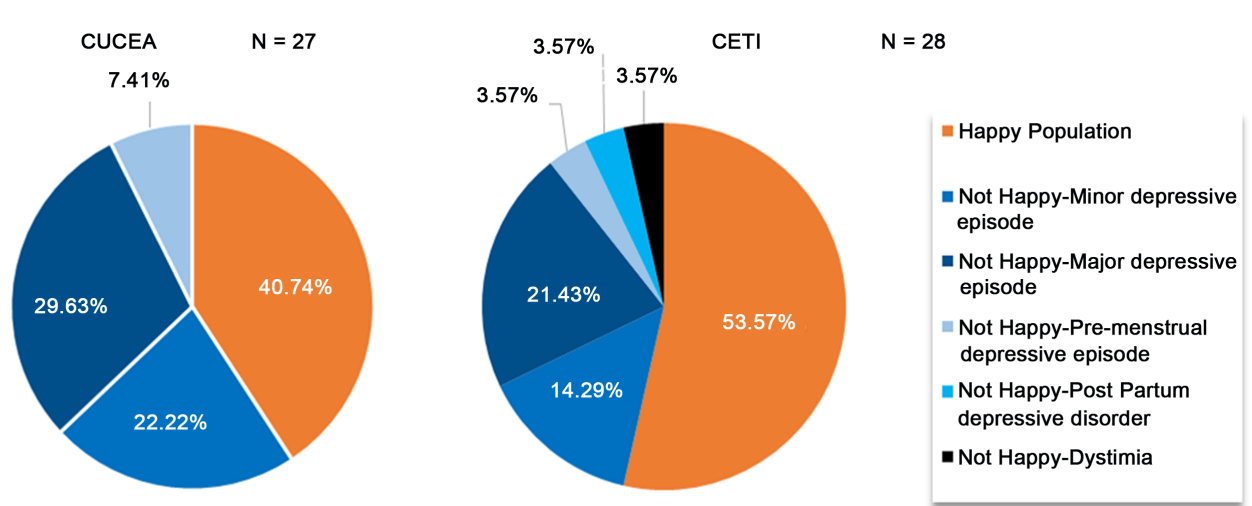

Figure 4. Results after users perform the HoD application test.

happy population due the fact that happiness is the rest of people that does not have any level of depression. Thus, this way we may estimate a percentage of public that is happy according to the results obtained under this approach.

\section{Conclusion}

The elements which compose a Smart City do not necessarily have to consist of environmental, infrastructural or economic factors, but also factors that pose a threat to the overall health of a Smart City's environment, which in regards to depression can be at risk, considering the fact that many people are unaware of its existence or refuse to accept that they may have fallen victim to it. As mentioned throughout this paper, making use of emerging application technology is paramount to the evolution of the living conditions encountered in the city.

\section{Acknowledgements}

Authors would like to thank the Science and Technology Council (CONACyT), the Information Technologies $\mathrm{PhD}$ at the University of Guadalajara and the Smart Cities Innovation Centre, Centro de Enseñanza Técnica Industrial (CETI), CETI student Espinoza López Javier, the PRODEP project for the funding received and the IEEE for their support in achieving this research.

\section{References}

[1] De Santis, R., Fasano, A., Mignolli, N. and Villa, A. (2016) Smart City: Fact and Fiction. MPRA, 2014. https://mpra.ub.uni-muenchen.de/54536/

[2] Hall, R.E. (2000) The Vision of a Smart City. 2nd International Life Extension Technology Workshop, Paris, France, September.

[3] Washburn, D. and Sindhu, U. (2010) Helping CIOs Understand "Smart City" Initiatives. Forrester Research, February.

http://www.uwforum.org/upload/board/forrester_help_cios_smart_city.pdf

[4] García, P. and McCarthy, M. (1994) Measuring Health-A Step in the Development of City Health. World Health Organization.

[5] De Choudhury, M., Counts, S. and Horvitz, E. (2013) Social Media as a Measurement Tool 
of Depression in Populations. WebSci'13, May, Paris, France, ACM 978-1-4503-1889-1.

[6] Kehua, S., Jie, L. and Hongbo, F. (2011) Smart City and the Applications. IEEE International Conference on Electronic, Communications and Control (ICECC), Ningbo, 9-11 September 2011, 1028-1031.

[7] Openshaw, M., Thompson, L.M., de Pheils, P.B., Mendoza, M.E. and Humpreys, J. (2015) Childhood Trauma Is Associated with Depressive Symptoms in Mexico City Women. Pan American Journal of Public Health, 37, 308-315.

[8] Shen, N., Levitan, M.J., Johnson, A., Bender, J.L., Hamilton-Page, M., Jadad, A.A.R. and Wiljer, D. (2015) Finding a Depression App: A Review and Content Analysis of the Depression App Marketplace. JMIR mHealth and uHealth, 3, e16.

[9] Vázquez, C., Hernangómez, L., Nieto, M. and Hervás, G. (2006) Evaluación de la depresión. En V. Caballo (ed.), Manual para la evaluación clínica de los trastornos psicológicos: Directrices prácticas e instrumentos de evaluación para niños, adolescentes y adultos. Pirámide, Madrid, 201-231.

[10] Morrison, J. (2014) DSM-5 Guía para el diagnóstico clínico. El manual moderno, New York, 108-170.

[11] Cohen, B. (2016) The Top 10 Smartest European Cities. http://www.fastcoexist.com/1680538/what-exactly-is-a-smart-city

[12] Harrison, C. and Donnelly, I.A. (2011) A Theory of Smart Cities. Proceedings of the 55th Annual Meeting of the ISSS-2011, Hull, 17-22 July 2011.

[13] Veenhoven, R. (2008) Healthy Happiness Effects of Happiness on Physical Health and the Consequences for Preventive Health Care. Journal of Happiness Studies, 9, 449-469.

[14] Amarú, L., Gaillardon, P.E. and De Micheli, G. (2014) Majority-Inverter Graph: A Novel Data-Structure and Algorithms for Efficient Logic Optimization. Proceedings of the 51 st Annual Design Automation Conference, San Francisco, 2-5 June 2014, 1-6. http://dx.doi.org/10.1145/2593069.2593158

Submit or recommend next manuscript to SCIRP and we will provide best service for you:

Accepting pre-submission inquiries through Email, Facebook, LinkedIn, Twitter, etc. A wide selection of journals (inclusive of 9 subjects, more than 200 journals)

Providing 24-hour high-quality service

User-friendly online submission system

Fair and swift peer-review system

Efficient typesetting and proofreading procedure

Display of the result of downloads and visits, as well as the number of cited articles Maximum dissemination of your research work

Submit your manuscript at: http://papersubmission.scirp.org/

Or contact jsea@scirp.org 